\title{
Polyhydroxybutyrate (PHB)-based Triblock Copolymers : Synthesis of Hydrophobic PHB/Poly(benzyl $\beta$-malolactonate) and Amphiphilic PHB/Poly(malic acid) Analogues by Ring-Opening Polymerization
}

\begin{abstract}
Ghislaine Barouti, ${ }^{a}$ and Sophie M. Guillaume, ${ }^{*}$
Polyhydroxyalkanoates (PHAs) are biocompatible and biodegradable polyesters widely used for biomedical applications. Amphiphilic triblock copolymers with PHB hydrophobic segment recently demonstrated attractive advantages such as high colloidal stability and low CMC (Critical Micellar Concentration) values for the elaboration of drug delivery systems. Our approach aims at associating PHB with a fully biodegradable hydrophilic block to access new self-assembled systems with unique potential. Well-defined $\alpha, \omega$-dihydroxy telechelic PHA-based hydrophobic triblock copolymers with tunable segments' length were synthesized by the controlled ring-opening polymerization (ROP) of benzyl $\beta$-malolactonate, using polyhydroxybutyrate $(\mathrm{PHB})$ diol/Nd(OTf) ${ }_{3}$ as catalytic system. Remarkably, the reaction proceeds with the selective oxygen-acyl bond cleavage of the $\beta$-lactone. The corresponding amphiphilic copolymers were then obtained by hydrogenolysis. These copolymers are the only examples of fully biodegradable PHA-PHB-PHA triblock copolymers. The hydrophilic weight fraction of the copolymers was tuned from 7 to $83 \%$ upon modulating the monomer loading thus affording the ability to next access to different self-assembling architectures.
\end{abstract}

Biodegradable polyesters have been widely studied during the past few decades for various specialty and commodity applications such as in packaging, tissue/bone engineering and drug delivery. ${ }^{1}$ Among these, poly(3-hydroxyalkanoate)s (PHAs) such as the ubiquitous poly(3-hydroxybutyrate) (PHB) or the more recently revisited poly( $\beta$-malic acid) (PMLA), are extremely attractive due to their additional biocompatibility and biodegradability. ${ }^{2}$

While natural PHAs can be produced by a number of bacteria, ring-opening polymerization (ROP) of the corresponding cyclic monomers -namely $\beta$-lactones such as $\beta$-butyrolactone $(\beta-B L)$ or benzyl $\beta$-malolactonate (MLA ${ }^{\mathrm{Be}}$ ) - is nowadays the most convenient, efficient, versatile and controlled method to synthesize welldefined tailored PHAs with controlled macromolecular characteristics (molar mass predictability, narrow dispersity, chainend fidelity, microstructure and tacticity). ${ }^{3,4}$ Moreover the high crystallinity of naturally produced isotactic PHB does not allow the high drug loading efficiency (DLE) of hydrophobic drugs, as the result of the low polymer chains mobility which makes the incorporation of the drug more difficult. Typically, ROP of $\beta$ lactones may occur through oxygen-alkyl or oxygen-acyl bond cleavage resulting in an inactive carboxylic acid chain-end or in an active hydroxyl terminus, respectively (Scheme 1). Another particularity of this process is the propensity for $\mathrm{H}_{2} \mathrm{O}$ abstraction resulting in an inactive crotonate end-capping group. ${ }^{3}$ Given the challenge in polymerizing these four

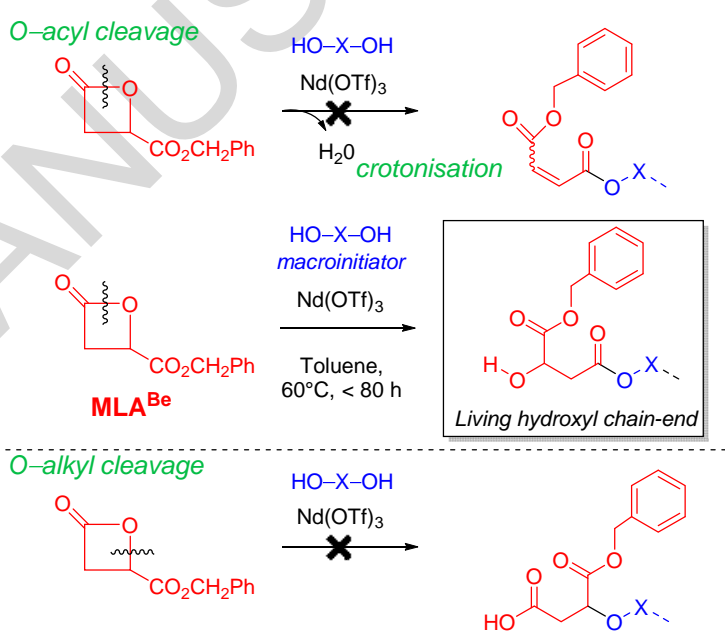

Scheme 1. Selectivity issues in the MLA ${ }^{B e}$ cleavage during its ROP initiated by a PHB macrodiol and catalysed by the neodymium triflate salt.

membered ring-strained lactones, the identification of an efficient and selective catalytic system (and to a lesser extent of the operating conditions) is the key point to achieve a good control of the ROP of $\beta$-lactones.

Whereas PHA-based $A B$ diblock copolymers are quite numerous, the analogous $A B A$ triblock copolymers are more limited mostly due to synthetic difficulties. The class of PHB-centered (B block) triblock copolymers includes a few reports with poly(ethylene oxide) A blocks, ${ }^{5}$ with other scarce examples of poly(lactide $)^{6 a, b}$ poly(trimethylene carbonate), ${ }^{6 c}$ poly( $N$-isopropyl acrylamide), ${ }^{6 \mathrm{~d}, \mathrm{e}}$ poly(methacrylate) ${ }^{6 \mathrm{f}}$ poly(tert-butyl acrylate) ${ }^{6 \mathrm{~g}}$ poly(2-(dimethyl-amino)ethyl methacrylate), ${ }^{6 \mathrm{~h}}$ poly(ethyl ethylene phosphate), ${ }^{6 i}$ and poly(styrene), ${ }^{6, j}$ often used within biomaterials.

The association of PHB with PMLA ${ }^{(\mathrm{Be})}$ in a triblock copolymer enables some modularity of the properties thanks to the benzyloxycarbonyl (poly(benzyl $\beta$-malolactonate), $\mathrm{PMLA}^{\mathrm{Be}}$ ) or carboxylic acid (PMLA) groups resulting in fully hydrophobic PHB/PMLA ${ }^{\text {Be }}$ or amphiphilic PHB/PMLA copolymers, respectively. In addition, using PHB and PMLA affords fully biodegradable selfassembling systems, whereas in most other PHB-based copolymers, 
only a hydrophilic block below a given molar mass is excreted by the renal system. Given that the PHB-b-PMLA diblock copolymer afforded promising non-cytotoxic micelles in aqueous solutions, ${ }^{7}$ the parent triblock copolymer PMLA- $b$-PHB- $b$-PMLA thus appears highly attractive due to its potential structuration which may be different as a function of the hydrophilic weight fraction, and which may impart valuable features for drug delivery applications. Indeed, micelles formed from triblock copolymers give more interpenetrated network with favored unimers exchange, thus allowing the possibility to reach a thermodynamic equilibrium. ${ }^{8}$

In this contribution, we report the first synthesis of well-defined hydrophobic PMLA ${ }^{\mathrm{Be}}-b-\mathrm{PHB}-b-\mathrm{PMLA}^{\mathrm{Be}}$ and of their corresponding amphiphilic PMLA- $b$-PHB- $b$-PMLA copolymers, based on the ROP of $\mathrm{MLA}^{\mathrm{Be}}$ from a PHB-diol macroinitiator and neodymium triflate catalyst $\left(\mathrm{Nd}(\mathrm{OTf})_{3} ; \mathrm{OTf}=\mathrm{CF}_{3} \mathrm{SO}_{3}\right)$, followed by hydrogenolysis of the benzyloxycarbonyl groups under mild conditions (Scheme 2). Along with the previously reported parent diblock copolymers PMLA ${ }^{(\mathrm{Be})}-b-$ $\mathrm{PHB}{ }^{7}$ these copolymers are, to the best of our knowledge, the first such set of analogous diblock and triblock hydrophobic and amphiphilic PHA copolymers. ${ }^{2 \mathrm{~d}}$

The PMLA ${ }^{\mathrm{Be}}-b-\mathrm{PHB}-b-\mathrm{PMLA}^{\mathrm{Be}}$ triblock copolymers were first synthesized by ROP of MLA ${ }^{\mathrm{Be}}$, using $\alpha, \omega$-dihydroxy telechelic $\mathrm{PHB}^{9}$ (Table S1, Fig. S1, ESIt) and $\mathrm{Nd}(\mathrm{OTf})_{3}$ as a new catalytic system (Scheme 2; Table 1), which proceeded through an activated monomer mechanism. ${ }^{10,11,12}$ The monomer conversion determined by ${ }^{1} \mathrm{H}$ NMR analysis of the crude reaction mixture and the reaction times were in the same range as those reported for the homopolymerization of $\mathrm{MLA}^{\mathrm{Be}}$ using $\mathrm{Nd}(\mathrm{OTf})_{3} /$ isopropanol or propanediol, ${ }^{11,12 d}$ thus highlighting the good efficiency of the dihydroxy functionalized PHB macroinitiator. Varying the $\mathrm{MLA}^{\mathrm{Be}}$

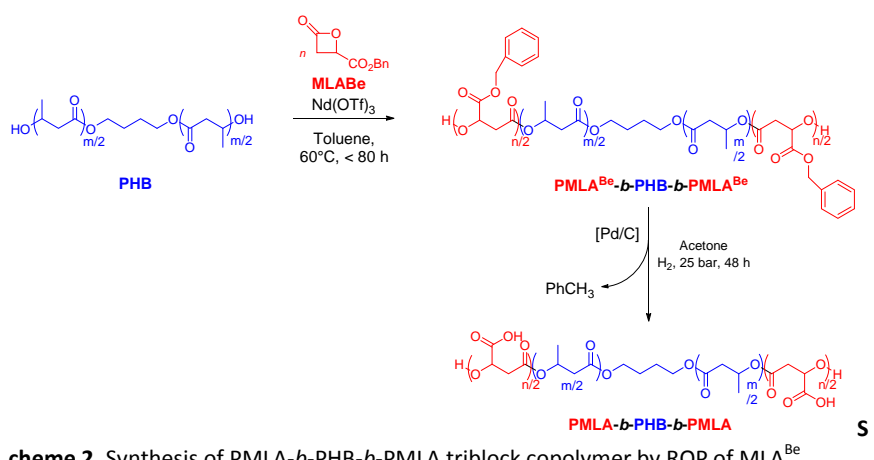

cheme 2. Synthesis of PMLA- $b$-PHB- $b$-PMLA triblock copolymer by ROP of MLA ${ }^{B e}$ initiated by $\mathrm{Nd}(\mathrm{OTf})_{3} / \mathrm{HO}-\mathrm{PHB}-\mathrm{OH}$, followed by hydrogenolysis.

initial loading (5-58 equiv.) and the molar mass of the initial PHB macroinitiator $\left(M_{\mathrm{n}, \mathrm{NMR}}=1400-6700 \mathrm{~g} \cdot \mathrm{mol}^{-1}\right.$, Table S1, ESI +$)$, enabled to get a series of $\mathrm{PMLA}^{\mathrm{Be}}-b-\mathrm{PHB}-b-\mathrm{PMLA}^{\mathrm{Be}}$ triblock copolymers with various lengths of each segment $\left(\mathrm{PMLA}^{\mathrm{Be}} / \mathrm{PHB}\right.$ ratios $=13: 87$ to $90: 10) .{ }^{13} \mathrm{~A}$ set of seven representative hydrophobic triblock copolymers $\left(M_{\mathrm{n}, \mathrm{NMR}}=3300-11500 \mathrm{~g} \cdot \mathrm{mol}^{-1}\right)$ was thus obtained in a few grams scale.

The triblock copolymers isolated after a single dialysis were characterized by ${ }^{1} \mathrm{H}$ NMR spectroscopy in acetone- $d_{6}$. The samples prepared from the highest MLA ${ }^{\mathrm{Be}}$ loading and the longest reaction time revealed that less than $10 \%$ of the copolymer chains were endcapped by a carboxylic acid group resulting from the oxygen-alkyl cleavage of the monomer (Table 1, entries 6,7; Fig. S2, Scheme 1, $\mathrm{ESI}+$ ). These $-\mathrm{COOH}$ end-functionalized macromolecules were however successfully eliminated by rapid elution of the copolymer sample through a short silica column, as evidenced by the disappearance of the corresponding signal in the ${ }^{1} \mathrm{H}$ NMR spectra of the recovered samples (vide infra, Fig. S5, ESIt). No signal characteristic of a crotonate chain-end $(\mathrm{C}(\mathrm{O}) \mathrm{CHCH}-\mathrm{C}(\mathrm{O}) \mathrm{OCH} 2 \mathrm{Ph}, \delta$ $6.85,5.80 \mathrm{ppm})^{12 \mathrm{c}-\mathrm{d}}$ was observed in the spectra of the triblock copolymers. Adjusting the operating conditions to a shorter polymerization time thus directly afforded PMLA ${ }^{\mathrm{Be}}-b-\mathrm{PHB}-b-\mathrm{PMLA}^{\mathrm{Be}}$ samples free of macromolecules with carboxylic acid or crotonate termini (Table 1), thereby supporting the selective $M L A^{B e}$ oxygen-acyl bond cleavage.

Table 1. ROP of $\mathrm{MLA}^{\mathrm{Be}}$ promoted by the $\mathrm{Nd}(\mathrm{OTf})_{3} / \mathrm{HO}-\mathrm{PHB}-\mathrm{OH}$ catalytic system and subsequent hydrogenolysis.

\begin{tabular}{|c|c|c|c|c|c|c|c|c|c|c|c|}
\hline Entry & $\begin{array}{c}{\left[\mathrm{MLA}^{\mathrm{Be}}\right]_{0}:} \\
{[\mathrm{PHB}]_{0}:} \\
{\left[\mathrm{Nd}(\mathrm{OTf})_{3}\right]_{0}^{\mathrm{a}}}\end{array}$ & $\begin{array}{l}\text { Reaction } \\
\text { Time }^{\mathrm{b}} \\
\text { (h) }\end{array}$ & $\begin{array}{l}\text { MLA }^{\mathrm{Be}} \\
\text { Conv. }^{\mathrm{C}} \\
(\%)\end{array}$ & $\begin{array}{c}\text { PHB } \\
M_{\mathrm{n}, \mathrm{NMR}}^{\mathrm{d}} \\
\left(\mathrm{g} \cdot \mathrm{mol}^{-1} \text { ) }\right.\end{array}$ & $\begin{array}{c}\text { PMLA }^{\mathrm{Be}}-b-\mathrm{PHB} \\
-b-\mathrm{PMLA}^{\mathrm{Be}} \\
M_{\mathrm{n}, \text { theoe }} \\
\left(\mathrm{g} \cdot \mathrm{mol}^{-1} \text { ) }\right.\end{array}$ & $\begin{array}{c}\text { PMLA }^{\mathrm{Be}}-b-\mathrm{PHB}-b- \\
\text { PMLA }^{\mathrm{Be}} \\
M_{\mathrm{n}, \mathrm{NMRf}} \\
\left(\mathrm{g} \cdot \mathrm{mol}^{-1}\right)\end{array}$ & $\begin{array}{c}\text { PMLA }^{\mathrm{Be}} / \\
\text { PHB NMR } \\
\text { molar mass } \\
\text { ratio }^{\mathrm{g}} \\
(\%)\end{array}$ & $\begin{array}{c}\text { PMLA }^{\mathrm{Be}}-b- \\
\text { PHB } \\
-b-\mathrm{PMLA}^{\mathrm{Be}} \\
M_{\mathrm{n}, \mathrm{sec}} \\
\text { (g.mol }{ }^{-1} \text { ) }\end{array}$ & $\bigoplus_{\mathrm{M}}{ }^{\mathrm{h}}$ & $\begin{array}{c}\text { PMLA- } b \text {-PHB- } b- \\
\text { PMLA } \\
M_{\mathrm{n}}{ }^{\mathrm{i}} \\
\left(\mathrm{g} \cdot \mathrm{mol}^{-1}\right)\end{array}$ & $\begin{array}{c}\text { PMLA/PHB } \\
\text { molar mass } \\
\text { ratio }^{j} \\
(\%)\end{array}$ \\
\hline 1 & $5: 1: 1$ & 7 & 94 & 2700 & $500-2700-500$ & $400-2500-400$ & $24: 76$ & 3300 & 1.29 & $200-2400-200$ & $14: 86$ \\
\hline 2 & $6: 1: 1$ & 10 & 96 & 6700 & $600-6700-600$ & $500-6500-500$ & $13: 87$ & 4700 & 1.33 & $250-6600-250$ & $7: 93$ \\
\hline 3 & $8: 1: 1$ & 12 & 100 & 3800 & $800-3800-800$ & $800-4600-800$ & $26: 74$ & 3100 & 1.26 & $400-4600-400$ & $15: 85$ \\
\hline 4 & $12: 1: 1$ & 40 & 100 & 2100 & $1200-2100-1200$ & $1200-1700-1200$ & $59: 41$ & 3200 & 1.24 & $600-1700-600$ & $41: 59$ \\
\hline 5 & $24: 1: 1$ & 60 & 100 & 4900 & $2500-4900-2500$ & $2200-4900-2200$ & $47: 53$ & 5600 & 1.23 & $1100-4600-1100$ & $32: 68$ \\
\hline 6 & $55: 1: 1$ & 80 & 100 & 2100 & $5700-2100-5700$ & $4100-2500-4100$ & $77: 23$ & 3100 & 1.50 & 2000-2500-2000 & $62: 38$ \\
\hline 7 & 58:1:1 & 80 & 98 & 1400 & 5900-1400-5900 & $5200-1100-5200$ & $90: 10$ & 3400 & 1.38 & $2600-1100-2600$ & 83:17 \\
\hline
\end{tabular}

${ }^{a}$ All reactions were run in toluene at $60{ }^{\circ} \mathrm{C}$ with an initial concentration of PHB prior to the addition of MLA ${ }^{B e}$ of $[\mathrm{PHB}]_{0}=0.1$ mol. $\mathrm{L}^{-1}$. ${ }^{\mathrm{b}}$ Reaction times were not necessarily optimized. ${ }^{\mathrm{C}} \mathrm{MLA}{ }^{\mathrm{Be}}$ conversion as determined by ${ }^{1} \mathrm{H}$ NMR spectroscopy of the crude reaction mixture (ESI $\dagger$ ). ${ }^{\mathrm{d}}$ Molar mass values of the HO-PHB-OH macroinitiator (not including either the terminal hydrogens or the $-\mathrm{O}\left(\mathrm{CH}_{2}\right)_{3} \mathrm{O}$ - central moiety) as determined by ${ }^{1} \mathrm{H}$ NMR spectroscopy of the isolated polymer in acetone- $d_{6}$ at $25{ }^{\circ} \mathrm{C}(\mathrm{Table} \mathrm{S} 1$, ESI $+{ })$. ${ }^{e}$ Theoretical molar mass values of HO-PMLA ${ }^{\mathrm{Be}}-b$-PHB- $b-\mathrm{PMLA}^{\mathrm{Be}}-\mathrm{OH}$ copolymers $\left(\mathrm{ESI}+{ }^{+}\right) .{ }^{\mathrm{f}}$ Molar mass values as determined by ${ }^{1} \mathrm{H}$ NMR analysis of the isolated block copolymer (ESI + ). ${ }^{\mathrm{g}}$ Molar mass ratio of the two blocks of the copolymer as determined by ${ }^{1} \mathrm{H}$ NMR spectroscopy. ${ }^{\mathrm{h}}$ Experimental molar mass and dispersity values as determined by SEC analysis in THF at $30^{\circ} \mathrm{C}$ vs. polystyrene standards (uncorrected $M_{\mathrm{n}}$ values; ESI + ). ${ }^{i}$ Molar mass values of HO-PMLA- $b$-PHB- $b$-PMLA-OH copolymers calculated upon dividing by two the PMLA ${ }^{B e}$ molar mass of the hydrophilic triblock copolymer (ESI+), and from the molar mass of PHB as determined by ${ }^{1} \mathrm{H}$ NMR analysis in acetone- $d_{6}$ of the isolated amphiphilic copolymer. Molar mass ratio of the PMLA and PHB segments within the copolymer based on the previously determined molar mass value (penultimate column); the first figure refers to the hydrophilic weight fraction

The purified copolymers were then thoroughly analyzed by NMR spectroscopy as $\alpha, \omega$-dihydroxy telechelelic PMLA ${ }^{\mathrm{Be}}-b-\mathrm{PHB}-b$ $\mathrm{PMLA}^{\mathrm{Be}}$. The ${ }^{1} \mathrm{H}$ NMR spectra of the copolymers showed the
distinctive signals corresponding to both $B L$ and $M L A^{\mathrm{Be}}$ repeating 
units and the central tetramethylene moiety, as illustrated Fig. 1 (Fig. S3-S5, ESI+). The good resolution of these latter methylene resonances enabled their fairly reliable integration from which both the PHB and PMLA ${ }^{\text {Be }}$ segments molar mass values $\left(M_{n, N M R}\right)$ could be determined. These data were in good agreement with the ones calculated from the monomer conversion and from the initial feed of MLA ${ }^{\mathrm{Be}}$ and of the initiator $\left(M_{n, \text { theo }}\right)$, as reported in Table 1 . The corresponding ${ }^{13} \mathrm{C}\left\{{ }^{1} \mathrm{H}\right\} \mathrm{J}-\mathrm{MOD},{ }^{1} \mathrm{H}-{ }^{13} \mathrm{C} \mathrm{HMBC}$ and ${ }^{1} \mathrm{H}-{ }^{13} \mathrm{C} \mathrm{HSOC}$ NMR spectra similarly evidenced and confirmed the presence of PHB and PMLA $^{\mathrm{Be}}$ units, and of the tetramethylene central moiety (Fig. S6-S8, ESI ${ }^{\dagger}$ ). Furthermore, DOSY NMR experiments are being more and more implemented to evidence the formation of block copolymers and to assess their purity. ${ }^{7,14}$ DOSY NMR analyses of the PMLA ${ }_{2200^{-}}$ $b-\mathrm{PHB}_{4900}-b-\mathrm{PMLA}^{\mathrm{Be}}{ }_{2200}$ triblock copolymer showed a single diffusion coefficient for all the signals, distinct from the two coefficients observed for a mixture of the PHB-diol macroinitiator and of a PMLA ${ }^{\mathrm{Be}}$ homopolymer with comparable molar mass to the triblock composition (Fig. 2). These results suggested the absence of contamination of the triblock copolymer by any homopolymer, and the presence of a single macromolecular species in the sample.

SEC analysis in THF of the purified triblock copolymer samples typically showed a trace shifted to a higher molar mass value as compared to that of the corresponding PHB macroinitiator (Fig. S9, $\mathrm{ESI}+$ ). No residual PHB macroinitiator was therein observed thus supporting the high efficiency of the macro-diol to initiate the ROP of $M L A^{B e}$, and that all polymer chains were initiated by $\mathrm{HO}-\mathrm{PHB}-\mathrm{OH}$. Monomodal chromatograms with narrow dispersity values $\left(\Theta_{\mathrm{M}}=\right.$ 1.23-1.50, ESI + ), along with the good agreement of $M_{n \text {,theo }}$ and $M_{\mathrm{n}, \mathrm{NMR}}$ values (vide supra, Table 1), suggested the good control of the polymerization. ${ }^{16}$

The amphiphilic $\alpha, \omega$-dihydroxy telechelic triblock copolymers HO-PMLA- $b$-PHB- $b$-PMLA-OH were next obtained upon hydrogenolysis of the parent hydrophobic copolymers HO-PMLA ${ }^{\mathrm{Be}}$ $b$-PHB- $b$-PMLA ${ }^{\mathrm{Be}}-\mathrm{OH}$ by using a heterogeneous $\mathrm{Pd} / \mathrm{C}$ catalyst under

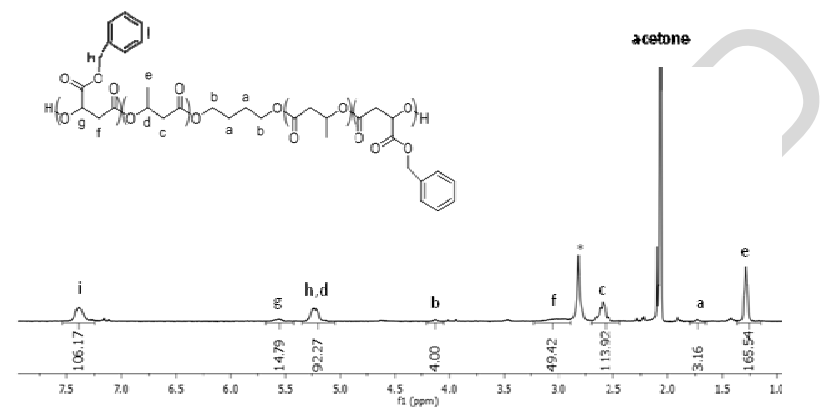

Fig. 1. ${ }^{1} \mathrm{H}$ NMR $\left(400 \mathrm{MHz}\right.$, acetone- $\left.d_{6}, 23^{\circ} \mathrm{C}\right)$ spectrum of HO-PMLA ${ }_{2200}-b-\mathrm{PHB}_{4900}-b-$ $\mathrm{PMLA}^{\mathrm{Be}}{ }_{2200} \mathrm{OH}$ synthesized by ROP of MLA ${ }^{\mathrm{Be}}$ from $\mathrm{Nd}(\mathrm{OTf})_{3} / \mathrm{OH}-\mathrm{PHB}_{4900}-\mathrm{OH}$ (Table 1 entry 5) (* marker stands for residual water). ${ }^{15}$

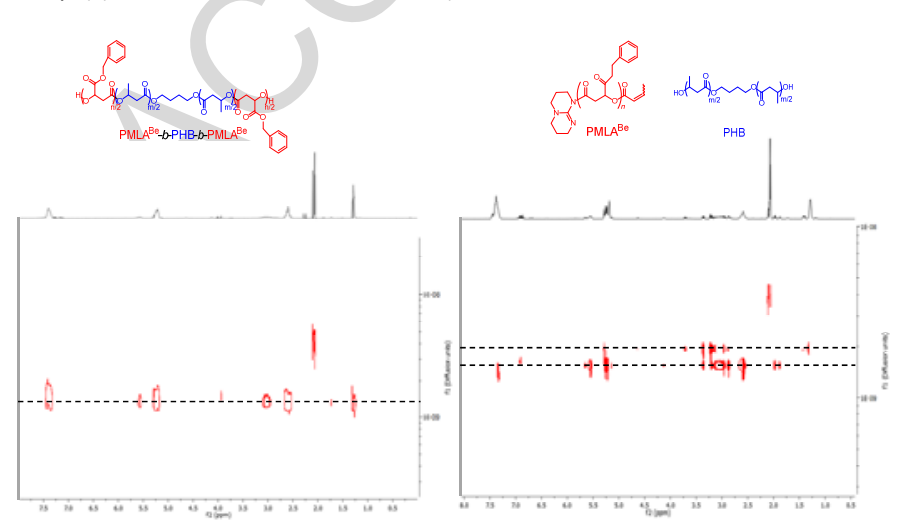

Fig. 2. DOSY NMR ( $400 \mathrm{MHz}$, acetone- $\left.d_{6}, 23^{\circ} \mathrm{C}\right)$ spectrum of $\mathrm{HO}-\mathrm{PMLA}^{\mathrm{Be}}{ }_{2200^{-} b-\mathrm{PHB}_{4900^{-}}}$ $b$-PMLA ${ }_{2200} \mathrm{Be}-\mathrm{OH}\left(\mathrm{D}=127.10^{-11} \mathrm{~m}^{2} \cdot \mathrm{s}^{-1}\right)$ synthesised by ROP of MLA ${ }^{\mathrm{Be}}$ from Nd(OTf) $3 / \mathrm{HO}$ $\mathrm{PHB}_{4900}-\mathrm{OH}$ (Table 1, entry 5) and of a mixture of HO-PMLA ${ }_{4000}^{\mathrm{Be}}$-crotonate (D = $\left.154.10^{-11} \mathrm{~m}^{2} \cdot \mathrm{s}^{-1}\right)$ and HO-PHB $5000-\mathrm{OH}\left(\mathrm{D}=191 \cdot 10^{-11} \mathrm{~m}^{2} \cdot \mathrm{s}^{-1}\right)$.

mild conditions (Scheme 2). This enabled the cleavage of the pendant benzyloxycarbonyl moieties of the MLA $^{\text {Be }}$ repeating units without alteration of the polymer backbone, a well-known abstraction method suitable for polyesters (Scheme 2). ${ }^{2 c, 7,14 a, 18}$ The amphiphilic PMLA- $b$-PHB- $b$-PMLA copolymers were then recovered as a viscous colorless oil after dialysis (Table 1 ).

In order to characterize these amphiphilic triblock copolymers by NMR spectroscopy, a good solvent of both segments needed to be identified. However, no common organic solvent (acetone, acetone/ trifluoroacetic acid (TFA), acetone/water, THF, DMSO, DMF, $\mathrm{CHCl}_{3}, \mathrm{CH}_{2} \mathrm{Cl}_{2}$ ) was found suitable to simultaneously solubilize both blocks. The amphiphilic character of the copolymer and the triblock architecture most likely enhanced the ability of the copolymer to somehow self-organize, thus compromising its solubility and characterization. Nevertheless, analysis in acetone- $d_{6}$ first evidenced the total disappearance of the benzylic signals of the pending benzyl protecting groups, thus supporting the complete deprotection of the PMLA ${ }^{\mathrm{Be}}$ segment into the PMLA block, and further showed a basically unchanged molar mass value of the PHB block after hydrogenolysis, as expected (Fig. S10, ESI+). Addition of some TFA to the above mentioned solvents $(2-50 \%, v / v)$, as successfully enabling the complete dissolution of the related PMLA$b$-PHB diblock copolymers, ${ }^{7}$ also failed to simultaneously solubilize both PHA segments of the triblock copolymers. The addition of $2 \%$ of TFA $(v / v)$ to acetone- $d_{6}$ only resulted in the cleavage of the hydrogen bonds thus allowing, in particular, to clearly observe the resonance of the PMLA pending $-\mathrm{COOH}$ groups (Fig. 3, S11-S13, ESI+).Yet, this did not enable to fully dissolve the PMLA segment thus precluding the evaluation of its molar mass by ${ }^{1} \mathrm{H}$ NMR spectroscopy. Nevertheless, the molar mass was estimated to theoretically amount to half the molar mass of PMLA ${ }^{\mathrm{Be}}$, as the result of the depletion of the benzyloxy groups (Be corresponds to half the molecular weight of $\mathrm{MLA}^{\mathrm{Be}}$ ) (Table 1). A series of amphiphilic triblock copolymers featuring various hydrophilic PMLA fractions $(f$ ca. 7-83\%) was thus successfully isolated.

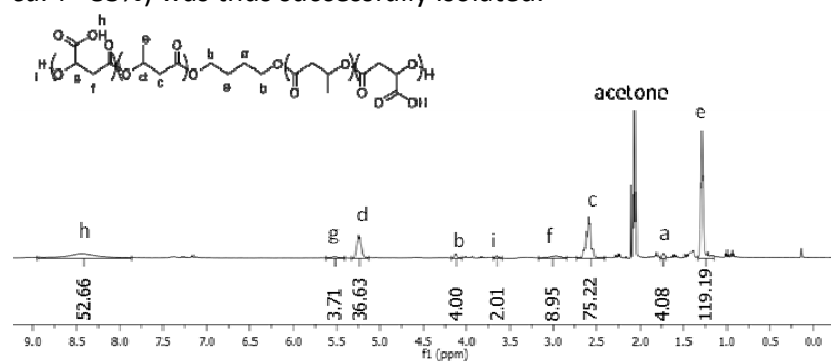

Fig. 3. ${ }^{1} \mathrm{H}$ NMR $\left(400 \mathrm{MHz}\right.$, acetone- $\left.d_{6} / \mathrm{TFA}(98: 02, v / v), 23^{\circ} \mathrm{C}\right)$ spectrum of HO-PMLA- $b$ PHB- $b$-PMLA-OH obtained upon hydrogenolysis of HO-PMLA ${ }_{2200}-b-\mathrm{PHB}_{4900}-b-$ $\mathrm{PMLA}^{\mathrm{Be}}{ }_{2200} \mathrm{OH}$ (Table 1, entry 5). The signals of the PHB and PMLA block do not suitably integrate as the result of the partial solubility of the triblock copolymer in this solvent.

The corresponding ${ }^{13} \mathrm{C}\left\{{ }^{1} \mathrm{H}\right\}$ J-MOD NMR spectra of the PMLA- $b$ PHB- $b$-PMLA copolymers in acetone- $d_{6} /$ TFA similarly evidenced the characteristic signals of PMLA and PHB segments and of the tetramethylene central moiety (Fig. S14, ESI + ). Moreover, DOSY NMR analyses of the amphiphilic copolymers revealed a single diffusion coefficient $\left(D=102.10^{-11} \mathrm{~m}^{2} \cdot \mathrm{s}^{-1}\right.$ ), different from that of the protected copolymer (Fig. 2 vs S15, ESI+), thus supporting that the sample fits well with a single-population model. ${ }^{19}$ All these NMR analyses showed that the hydrophobic triblock copolymers were smoothly chemically modified into their parent amphiphilic copolymers without fragmentation of the backbone and blocks. 
Furthermore, the surprisingly lower D value of the lower molar mass deprotected triblock copolymer as compared to the protected precursor, hinted that these triblock copolymers behaved distinctively than the analogous hydrophobic/amphiphilic diblock copolymers. ${ }^{7}$ This also suggested that not only the hydrophilic weight fraction $f$ of an amphiphilic copolymer is important to understand its physico-chemical behavior, but also that its architecture as a diblock or triblock copolymer also dictates to some extent its behavior in solution. The copolymer chemical composition-architecture-solution behavior relationship is thus a significant notion to investigate to better understand these PHAs triblock copolymers.

The thermal properties of PMLA ${ }^{\mathrm{Be}}-b-\mathrm{PHB}-b-\mathrm{PMLA}^{\mathrm{Be}}$ and PMLA$b$-PHB- $b$-PMLA were investigated by differential scanning calorimetry (DSC) and thermogravimetric analysis (TGA) (Fig. S17, S18, ESIt). The hydrophobic triblock copolymer (Table 1, entry 7) showed two glass transitions temperatures $\left(T_{\mathrm{g}}=+1,+26^{\circ} \mathrm{C}\right.$, corresponding to the $\mathrm{PHB}$ and $\mathrm{PMLA}^{\mathrm{Be}}$ blocks, respectively (ESI + ). a behavior similarly observed for PHB- $b-$ PMLA $^{\mathrm{Be}}$ copolymers. $^{7}$ The thermal degradation of the hydrophobic copolymers was found to be much slower and to occur at a higher temperature than that of the corresponding amphiphilic copolymers ( $f 1,83$; Table 1 , entries $4,7)$, respectively. Both sets of triblock copolymers exhibited a stepwise degradation profile corresponding to the degradation of first the PMLA ${ }^{(\mathrm{Be})}$ segment and then the PHB segment, as similarly observed for the PHB- $b$-PMLA ${ }^{(\mathrm{Be})}$ copolymers. $^{7}$ (ESI+). These thermal behaviors again highlighted the significant effect of the chemical composition/modification of the segment(s) of the block copolymers.

In summary, well-defined analogous hydrophobic and amphiphilic PHA-based triblock copolymers were successfully synthesized from commercially available reagents (except for $\mathrm{MLA}^{\mathrm{Be}}$ ), by the efficient and controlled ROP of MLA ${ }^{\mathrm{Be}}$ using a PHB diol/Nd(OTf) ${ }_{3}$ catalytic system nicely mediating the selective oxygen-acyl bond cleavage of the $\beta$-lactone, followed by hydrogenolysis. These copolymers represent, to our knowledge, the only examples of PHA-PHB-PHA triblock copolymers. This strategy could be extended to the design of other $\mathrm{PHA}$-based $A B A$ and $B A B$ triblock copolymers. These novel $\alpha, \omega$-dihydroxy telechelic triblock PHA copolymers are highly valuable. Indeed, they may also serve as macroinitiators towards the synthesis of other types of block copolymers. Also, thanks to the pending $-\mathrm{COOH}$ moieties, they provide anchoring sites for biological molecules of interest towards conjugated polymers. Finally, through their amphiphilicity, they may be valorized as nanostructured entities for drug delivery systems. Investigations of the self-assembling behavior of the PMLA- $b$-PHB- $b$-PMLA copolymers revealed unique properties in relation to the hydrophilic weight fraction. Detailed results and outcomes along these lines will be reported in due course.

This work was supported by the Fondation pour la Recherche Médicale (FRM, Ph.D. grant to G.B.). C. Orione and T. Reynaldo are gratefully acknowledged for their help with NMR and TGA experiments, respectively.

\section{Notes and references}

1. (a) B. D. Ulery, L. S. Nair, C. T. Laurencin J. Polym. Sci. Part B: Polym. Phys. 2011, 49, 832; (b) H. Tian, Z. Tang, X. Zhuang, X. Chen, X. Jing, Prog. Polym. Sci. 2012, 37, 237; (c) R. J. Pounder, A. P. Dove, Polym. Chem. 2010, 1, 260; (d) D. J. A.; Cameron, M. P. Shaver, Chem. Soc. Rev., 2011, 40, 1761.

2. (a) B. Laycock, P. Halley, S. Pratt, A. Werker, P. Lant, Prog. Polym. Sci., 2013, 38, 536; (b) S. Taguchi, T. Iwata, H. Abe, Y. Doi, Polym. Sci.: A Comprehensive Ref., 2012, 9, 157; (c) D. B.
Hazer, E. Kilicay, B. Hazer, Mater. Sci. and Eng. C, 2012, 32, 637; (d) C. Jaffredo, S. M. Guillaume Polym. Chem. 2014, 5, 4168; (e) Ljubimova, J. Y.; Fujita, M.; Ljubimov, A. V.; Torchilin, V. P.; Black, K. L.; Holler, E. Nanomedicine 2008, 3, 247-265; (f) King, S. L.; Truong, V. X.; Kirchhoefer, C.; PittoBarry, A.; Dove, A. P. Green Materials 2014, 2, 107-122.

3. (a) O. Coulembier, P. Dubois, in Handbook of Ring-Opening Polymerization; P. Dubois, O. Coulembier, J.-M. Raquez Eds.; Wiley-VCH, 2009; p 227; (b) J.-F. Carpentier, Macromol. Rapid Commun. 2010, 31, 1696; (c) C. M. Thomas, Chem. Soc. Rev. 2010, 39, 165

4. (a) W. N. Ottou, H. Sardon, D. Mecerreyes, J. Vignolle, D. Taton Prog. Polym. Sci., 2016, in press, doi:10.1016/j.prog polymsci.2015.12.001; (b) M. Fèvre, J. Vignolle, Y. Gnanou, D. Taton, Polym. Sci.: A comprehensive Ref., 2012, 4, 67.

5. (a) J. Li, X. Li, X. Ni, K. W. Leong, Macromolecules, 2003, 36, 2661; (b) T.-H. Kim, C. W. Mount, W. R. Gombotz, S. H. Pun, Suzie H. Biomaterials, 2010, 31, 7386; (c) J. Li, X. Ni, X. Li, N. K. Tan, C. T. Lim, S. Ramakrishna, K. W. Leong, Langmuir, 2005, 21, 8681; (d) X. Li, J. Li, K. W. Leong, Polymer, 2004, 45, 6845; (e) T. H. Kim, C. W. Mount, B. W. Dulken, J. Ramos, C. J. Fu, H. A. Khant, W. Chiu, W. R. Gombotz, S. H. Pun, Molecular Pharmaceutics, 2012, 9, 135 ; (f) J. Li, X; Li, X. Ni, X. Wang, H. Li, K. W. Leong, Biomaterials, 2006, 27, 4132; (g) X. Li, K. Y. Mya, X. Ni, C. He, K. W. Leong, J. Li, J. Phys. Chem. B, 2006, 110, 5920.

6. (a) J. P. MacDonald, M. P. Parker, B. W. Greenland, D. Hermida-Merino, I. W. Hamley, M. P. Shaver, Polym. Chem., 2015, 6, 1445; (b) D. C. Aluthge, C. Xu, N. Othman, N. Noroozi, S. G. Hatzikiriakos, P. Mehrkhodavandi, Macromolecules, 2013, 46, 3965;(c) S.-Y. Dai, L. Xue, Z. Li, Zhi, ACS Catalysis, 2011, 1, 1421 ; (d) X. J. Loh, J. Gong, M. Sakuragi, T. Kitajima, M. Liu, J. Li, Y. Ito, Macromol. Biosci., 2009, 9, 1069; (e) X. J. Loh, W. C. D. Cheong, J. Li, Y. Ito, Soft Matter 2009, 5, 2937; (f) H. Arslan, A. Mentes, B. Hazer, J. Appl. Polym. Sci., 2004, 94, 1789; (g) X. Zhang, H. Yang, Q. Liu, Y. Zheng, H. Xie, Z. Wang, R. Cheng, J. Polym. Sci., Part A: Polym. Chem., 2005, 43, 4857; (h) X. J. Loh, S. J. Ong, Y. T. Tung, H. T. Choo, Macromol. Biosci., 2013, 13, 1092; (i) J. Cheng, J. Wang, Sci. in China, Series B: Chemistry, 2009, 52, 961; (j) M. A. Abdelwahab, E. Martinelli, M. Alderighi, E. Grillo Fernandes, S. Imam, A. Morelli, E. Chiellini, J. Polym. Sci., Part A: Polym. Chem., 2012, 50, 5151.

7. G. Barouti, K. Jarnouen, S. Cammas-Marion, P. Loyer, S. M. Guillaume, Polym. Chem. 2015, 6, 5414.

8. (a) J. Lu, F. S. Bates, T. P. Lodge, Macromolecules 2015, 48, 2667 ; (b) C. Charbonneau, M. M. De Souza Lima, C. Chassenieux, O. Colombani, T. Nicolai, Phys. Chem. Chem. Phys. 2013, 15, 3955.

9. A. Couffin, B. Martín-Vaca, D. Bourissou, C. Navarro, C. Polym. Chem. 2014, 5, 161.

10. Note that, the sequential one-pot copolymerization of $B L$ followed by $\mathrm{MLA}^{\mathrm{Be}}$ catalyzed by HOTf at $30^{\circ} \mathrm{C}$ could not be implemented in light of the partial degradation of $\mathrm{MLA}^{\mathrm{Be}}$ in the presence of this strong protic acid. ${ }^{11}$

11. G. Barouti, C. G. Jaffredo, S. M. Guillaume, Polym. Chem., 2015, 6, 5851.

12. (a) N. Ajellal, J.-F. Carpentier, C. Guillaume, S. M. Guillaume, M. Helou, V. Poirier, Y. Sarazin, A. Trifonov, Dalton Trans. 2010, 39, 8363; (b) S. M. Guillaume, J.-F. Carpentier, Catal. Sci. Technol., 2012, 2, 898; (c) C. G. Jaffredo, J.-F. Carpentier, S. M. Guillaume, Polym. Chem., 2013, 4, 3837; (d) C. G. Jaffredo, J.-F. Carpentier, S. M. Guillaume, Macromolecules, 2013, 46, 6765.

13. The molar mass values of the initial $P H B$ segment remaining constant throughout the ROP of $\mathrm{MLA}^{\mathrm{Be}}$, and the good

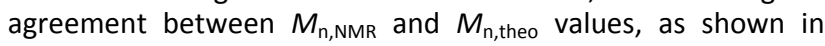
Table 1 , ruled out significant transesterification reactions. Also, the reasonable $\left(\theta_{M}=1.23-1.50\right)$ values hinted the occurrence of some, yet limited, side reactions (typically 
intermolecular (reshuffling) and intramolecular (back-biting) transesterification reactions and/or other chain transfer or termination reactions), and/or an initiation somewhat slower than the propagation. Furthermore, these dispersity values are in the range of those typically obtained for PMLA $^{\text {Be }}$ homopolymers and PMLA ${ }^{\text {Be }}$ /PHB copolymers. ${ }^{11,12,18 a, c}$

14. (a) G. Barouti, A. Khalil, C. Orione, K. Jarnouen, S. CammasMarion, P. Loyer, S. M. Guillaume, Chem. Eur. J-A European J. 2016, 22, 2819; (b) S. Paul, C. Romain, J. Shaw, C. K. Williams, Macromolecules 2015, 48, 6047; (c) F. Coumes, V. Darcos, D. Domurado, S. Li, J. Coudane, J. Polym. Chem. 2013, 4, 3705; (d) C. F. Hansell, P. Espeel, M. M. Stamenovic, I. A. Barker, A. P. Dove, F. E. Du Prez, R. K. O'Reilly, J. Am. Chem. Soc. 2011, 133, 13828; (e) S. Viel, M. Mazarin, R. Giordanengo, T. N. T. Phan, L. Charles, S. Caldarelli, D. Bertin, Anal. Chim. Acta 2009, 654, 45.

15. Surprisingly, the integral value of the $P M L A{ }^{\mathrm{Be}}$ methine mainchain resonance $\left(\mathrm{OCH}\left(\mathrm{CO}_{2} \mathrm{CH}_{2} \mathrm{C}_{6} \mathrm{H}_{5}\right) \mathrm{CH}_{2} \mathrm{C}(\mathrm{O}), \delta 5.52 \mathrm{ppm}\right)$ is much lower than expected, regardless of the value of the rela-xation delay (increased up to $10 \mathrm{~s}$ ), similarly to some spectra of the related PMLA ${ }^{\mathrm{Be}}$-n-ols, ${ }^{11}$ and as opposed to PHB- $b-$ PMLA $^{\text {Be }}$ copolymers ${ }^{7}$ which featured a correct integral value.

16. Note that, the experimental molar mass values assessed by SEC analyses in THF $\left(M_{\mathrm{n}, S E C}\right.$, Table 1$)$ also fairly matched the PMLA $^{\mathrm{Be}}-b$-PHB- $b$-PMLA ${ }^{\mathrm{Be}} M_{\mathrm{n}, \mathrm{NMR}}$ and $M_{\mathrm{n}, \text { theo }}$ data for the copo-lymers featuring short PMLA ${ }^{\mathrm{Be}}$ blocks. Indeed, $M_{\mathrm{n}, \mathrm{SEC}}$ of $\mathrm{MLA}^{\mathrm{Be}}$-enriched copolymers ( $\mathrm{ca}$. > 15 molar mass\%) remained lower than the expected values, possibly reflecting the adsorption of these copolymers onto the columns. Such a behaviour was previously observed for related PMLA ${ }^{\mathrm{Be}}$ and PMLA ${ }^{\text {Be } / P H B ~(c o) p o l y m e r s . ~}{ }^{711,12 c-d, 14 a, 17}$

17. (a) M. Helou, G. Moriceau, Z. W. Huang, S. Cammas-Marion, S. M. Guillaume Polym. Chem. 2011, 2, 840; (b) C. G. Jaffredo, J.F. Carpentier, S. M. Guillaume, Macromol. Rapid Commun. 2012, 33, 1938.

18 (a) C. G. C. Jaffredo, Y. Chapurina, S. M. Guillaume, J.-F. Carpentier, Angew. Chem., Int. Ed., 2014, 53, 2687; (b) R. J. Pounder, D. J. Fox, I. A. Barker, M. J. Bennison, A. P. Dove, Polym. Chem., 2011, 2, 2204; (c) Coulembier, O.; Degee, P.; Dubois, P., Macromol. Chem. Phys. 2006, 207, 484.

19. The DOSY NMR spectrum of a PMLA and PHB mixture cannot be acquired since no solvent can solubilize these two homopolymers simultaneously. 